\title{
LA PALABRA Y LA CULTURA EN LA ORGANIZACIÓN ${ }^{1}$
}

\author{
THE WORD AND CULTURE IN THE ORGANIZATION
}

\section{Rosa Nely Pérez Martínez ${ }^{2}$}

Para citar este artículo: Pérez, R. (2012). "La palabra y la cultura en la organización". Revista Inquietud Empresarial. Vol. XX, No 20, p.p. 79-90

Fecha de recepción: 3 de septiembre de 2012 Fecha de Aceptación: 2 de noviembre de 2012

\footnotetext{
1 Artículo de Reflexión como resultado del proyecto de investigación titulado "La Patología Autista en la Organización: Una interpretación a partir de la metáfora biológica". Realizado en el marco de la Maestría en Administración de la Universidad Nacional de Colombia.

2 Administradora de Empresas de la UPTC, Especialista en Gerencia Financiera y Magíster en Administración de la 2 Administradora de Empresas de la UPTC, Especialista en Gerencia Financiera y Magíster en Administración de la
Universidad Nacional de Colombia. Docente de la Escuela de Administración de Empresas de la UPTC, nelyperezm@yahoo. com.
} 


\section{RESUMEN}

Este escrito está construido desde una posición crítica, dentro del marco del Humanismo Radical, de las prácticas inhumanas en la organización asociadas con el uso del lenguaje y la palabra, dentro de la cultura organizacional de cualquier empresa. Es una revisión de fuentes secundarias, de investigaciones que dan cuenta de la calidad de las relaciones entre los integrantes de la organización, tanto en empresas nacionales como extranjeras. Se pretende generar en el lector una reflexión acerca del impacto que tiene la palabra en el comportamiento de aquellas personas que hacen parte de la entidad social, especialmente en lo que se refiere a subalternos.

\section{PALABRAS CLAVE}

Palabra, lenguaje, cultura, comportamiento, violencia verbal, conflicto.

\section{ABSTRACT}

This paper is constructed from a critical position within the framework of Radical Humanism, the inhuman practices in the organization associated with the use of language and words, within the organizational culture of any company. It is a review of secondary sources of research that realize the quality of relationships between members of the organization, both domestic and foreign companies. It aims to create in the reader a reflection about the impact of the word in the behavior of those who are part of the social entity, especially in regard to subordinates.

\section{KEY WORDS}

Word, language, culture, behavior, verbal violence, conflict.

\section{INTRODUCCIÓN}

Se parte de los conceptos de lenguaje, lengua y habla como forma de ubicación básica de la temática pertinente a la palabra en la organización. Cómo el lenguaje y su uso se convierten en elementos diferenciadores de la cultura organizacional en distintas empresas, gracias a la evidencia de investigaciones realizadas en Canadá y Colombia. Estas investigaciones están enmarcadas dentro de un cuerpo teórico que ha cuestionado sistemáticamente los modos y las formas propias de Management occidental eficientista. Este artículo aborda el lenguaje no verbal y su violencia implícita en relación con el personal subalterno en las empresas y el modo en 
que éstos se protegen contra ella. Por último, se exalta la importancia de la palabra como elemento de construcción o destrucción del individuo y en la percepción de la calidad de las relaciones en la organización.

\section{Referentes Teóricos}

Por lenguaje se entiende como el conjunto de sonidos articulados con que el hombre manifiesta lo que piensa o siente (RAE, 2001). La esencia del lenguaje humano yace en la colocación apropiada de las palabras en las oraciones de tal manera que se determina lo que ellas representan o son signo (Wittgenstein, 1999). La comprensión que el individuo hace para sí de esta cadena de palabras con sentido, que es la oración, evidencia la comunicación y ésta no se limita a la existencia de un lenguaje verbal, también esta soportada en un sistema de señales y signos distintos. El punto de encuentro entre comunicación y lenguaje subyace, según Serres (1996) en que la comunicación aparece como una especie de metalenguaje que permite pensar y hacer todo lo demás, en otras palabras invita a la acción.

De otra parte, en palabras de Chomsky, una de las razones para estudiar el lenguaje la constituye el hecho de que le resulta tentador considerarlo como "espejo de la mente" en un sentido profundo y significativo: un producto de la inteligencia humana creado de nuevo en cada individuo mediante operaciones que se encuentran más allá de la voluntad y de la conciencia (Chomsky, 1975). El lenguaje, sobrepasa esta dimensión natural e íntima del individuo para convertirse en una facultad universal, diferenciado de la lengua que es un sistema de expresiones particulares de una comunidad y distinto del habla que es el uso individual del sistema (Saussure, 1945) y precisamente de ésta última, del habla, en un espacio específico: la organización, es donde se centra esta reflexión.

El lenguaje es un tema de reciente construcción dentro de la teoría de la organización y se encuentra dentro del ámbito de la cultura humanista en general. En Colombia se le conoce como Estudios Críticos de Gestión a una serie de reflexiones que dan cuenta de prácticas inhumanas usadas como dispositivos de control en las organizaciones (Saavedra, 2009) en las que el uso del lenguaje y su significado construyen y preservan el statu quo o el orden dentro de la entidad social. La palabra, como manifestación del habla, es una capacidad eminentemente humana, nacemos con ella, es la materia prima en la construcción de "nuestra" identidad y la del "otro" a través del intercambio verbal. En éste intercambio, las mayoría de las veces, también es posible utilizar la palabra para ejercer influencia sobre las actitudes y comportamientos del "otro" (Chanlat \& Bédard, 1997), es decir, inducir a la acción o también a la inmovilización. 
De otro lado, la cultura de acuerdo con la concepción gramciana no está ligada al saber enciclopédico; es la conquista por la cual se llega a comprender el valor histórico del individuo en función de su vida, sus derechos y sus deberes (Gramsci, 1916). Para él, el empresario capitalista es el organizador de una nueva cultura ya que domina conocimientos técnicos próximos a la producción económica (Gramsci, 1967). Las relaciones de carácter subjetivo que necesariamente se dan entre los seres humanos, los cuales han sido influidos por instituciones diversas como la familia, la comunidad, la religión, etc., nutren a las organizaciones (Hatch, 1997) ofreciendo variables diversas para identificar un organismo social de otro, una empresa de otra. En el actual mundo corporativo, la cultura es un reforzador de conductas productivas eficientistas, dado que es la capacidad supuesta de un grupo dado (los gerentes) de suscitar, reforzar o modificar los valores, actitudes y creencias que se han revelado o que se revelan eficaces, para el conjunto de los miembros, y esto gracias a los ritos, ceremonias, símbolos y mitos apropiados (Aktouf, 2002). Es en esta especie de abuso de la "cultura organizacional" en la que se desarrolla la presente reflexión

Existe abundante literatura en la disciplina administrativa que muestra cómo el uso de la palabra promueve ciertos comportamientos en los participantes en la organización e incluso fuera de ella. Las frases estereotipadas o de cajón son de amplio espectro cuando de "motivar "al empleado se trata, hasta cuando se intenta con ella estimular el consumo de determinado producto y en éste aspecto es donde el mundo de la publicidad ha hecho lo suyo. Aquí, no puedo dejar de invitar el lector a que examine el contenido de las comunicaciones y del lenguaje de Etkin al referirse al tema de la doble moral de las organizaciones, (Etkin, 1993).

\section{DESARROLLO}

El propósito de la presente reflexión es mostrar al lector los resultados de observaciones, realizadas por reconocidos investigadores organizacionales, referentes al uso del lenguaje y su relación estrecha con la "cultura organizacional". Particularmente, se muestran evidencias donde este tipo de "cultura" resalta la violencia y el abuso en el lenguaje verbal y corporal, existentes en las relaciones entre supervisores y subordinados.

El lenguaje y la cultura:

En las investigaciones realizadas entre 1978 y 1986 por Omar Aktouf en ocho empresas distintas, tanto en Canadá como en Argelia dedicadas a la fabricación de pulpa de papel, se buscaba establecer si estos grupos sociales contaban con los elementos constitutivos para hablar de cultura ${ }^{3}$ organizacional y si se

3 Para Aktouf la cultura en una cosa demasiado vasta, demasiado importante como para encerrarla en una sola frase. Propone algunos elementos que la constituyen que van desde aquello que hace la vida en común de quienes participan en una organización, hasta un conjunto de representaciones mentales que ligan lo material con lo inmaterial. 
encontraban manifestaciones de un ambiente hostil al que el uso del lenguaje hubiera contribuido (Aktouf, 2002). A continuación se muestran algunos de los hallazgos encontrados:Ruptura casi radical entre directivos y empleados.

- Ausencia de comunicación o de lazos directos, excepto en ocasiones particulares, tales como el año nuevo.

- Abolición de voz: si expresarse no es prohibido, al menos es desincentivado y mal visto.

- Contradicciones flagrantes entre discursos y actos.

- No hay ninguna referencia diferente al frío lenguaje institucional, a una cercanía entre líderes y empleados.

En expresión de Aktouf, estos elementos dan cuenta de la separación que existe entre los dirigentes y los dirigidos, separación evidenciada en el uso y no uso del lenguaje, referidos en tercera persona: "ellos", "esos otros", etc. Esta es una evidencia del uso del lenguaje como elemento que identifica a una organización, es este caso, a través de un comportamiento hostil generalizado.

Siguiendo con Aktouf (2002) en el lenguaje de los directivos, los obreros y los empleados, son o están:

- Dotados de una "sucia mentalidad"

- Incapaces de tener disciplina

- Siempre a la "búsqueda del menor esfuerzo"

- "Ignorantes de su propio interés"

- La mayoría son "ovejas negras"

- Son "refunfuñones"

- "Llorones que dicen todo tipo de mentiras"

En boca de los obreros y de los empleados, los dirigentes o supervisores son:

- La "NASA" (personas que se creen grandes sabios)

- "Faraones"

- "Dioses sobre la tierra"

- "Desconocidos" que casi nunca hemos visto

- Gente "que ni siquiera te mira" 
- Los llamados "cerebros"

- Gente "que está allí para crear tensión"

- Gente "sin corazón"

- Gente "interesada por la producción iy punto!"

- Gente de "dos caras", "hipócritas"

- "Que te presionan en la espalda"

- "Fustigadores"

- Gente "con la que es mejor no tener que hablar", a quienes "nos negamos a estrecharles la mano", etc.

Este ambiente corresponde a empresas altamente jerarquizadas (ocho niveles para cuarenta empelados), altos niveles de control de operaciones, especialmente el tiempo, vigilancia permanente y reglas expresas. Por supuesto no hablar es una de ellas.

Por otra parte, y dentro del mismo ejercicio investigativo realizado por Aktouf, se presenta un lenguaje diametralmente distinto. El de una empresa que ha logrado una cultura organizacional monolítica, altamente establecida y fortalecida: Las siguientes son las observaciones realizadas por el investigador en las que el lenguaje cobra un especial significado:

- Ningún discurso del tipo "cultura organizacional"

- Los dirigentes no cesan de repetir que "no serían nada sin los obreros"

- Ningún signo llamativo de diferencias de estatus

- Confianza, escucha, diálogo

- El presidente en persona tiene su oficina y su teléfono abiertos a todos

- La palabra, la escucha y el contacto directo son generalizados

- Saltarse la jerarquía es corriente y aceptado

- Todas las informaciones (aun las tradicionalmente consideradas como confidenciales) se colocan en las carteleras: ventas, utilidades, pedidos, etc.

Otros elementos de la cultura organizacional, en la visión de Aktouf, fueron 
identificados en la empresa canadiense Cascades (Aktouf, 1995), durante el periodo de tiempo en el que duró la investigación. En estas observaciones se evidencian innovadoras prácticas, libres de presiones y sobre todo, auténticas:

- No hay referencia a los jefes en tercera persona (ellos, esos, esos otros, etc.)

- Real y verdadera calidez en la comunicación

- Con todos la acogida fue sumamente relajada, incluso amistosa y jovial.

- Contrariamente a otras empresas ya estudiadas en los mismos aspectos, se comprobó que en la dirección general había una verdadera "bulimia del habla".

- Todos estos altos ejecutivos daban la impresión de ser personas que usaban la palabra intensivamente; y que querían hablar de su empresa. De hecho, ni siquiera esperaban nuestras preguntas y, cuando nosotros creíamos haber terminado, siempre tenían "cosas que agregar" por propia iniciativa.

En boca de los dirigentes refiriéndose a los empleados:

- "Nuestro principal capital es el capital humano; debemos cuidarlo",

- "Sin los obreros no estaríamos acá"

- "Es preciso que los empleados vivan y sientan la compañía como suya"

- "No por ser directores vamos a evitarlos o humillarlos"

- "Nos esforzamos por conducimos con ellos como personas comunes y corrientes"

- "Los obreros tienen derecho a ser escuchados por cualquiera de nosotros"

- "Nuestros empleados nos juzgan por lo que hemos hecho por ellos"

- "No es suficiente hablar y prometer"

- "Si un nuevo responsable no abre sus puertas, éstas serán derribadas..."

Estas empresas y otras han sido referidas por Aktouf dentro de un marco de administración renovada en varios continentes, donde el leguaje adquiere un significado profundo que permite una visión compartida de la empresa y un 
compromiso distinto de los colaboradores hacia la misma. Empresas como Semco en Brasil, Benoit en Francia, Forbo en Quebec, son ejemplos de ésta nueva dinámica donde los modelos clásicos de administración no existen y su construcción se basa en una humanización del individuo a través de la dignificación del trabajo que realizan (Aktouf, 1998).

El chismorreo y la violencia verbal

La palabra "chisme" está definida por la RAE (Real Academia de Lengua Española) como: noticia verdadera o falsa, o comentario con que generalmente se pretende indisponer a unas personas con otras o se murmura de alguna. Sin embargo, el chismorreo tiene una gran valía dentro de los grupos informales, según Chanlat y Bédard porque construyen y refuerzan en sus creencias y valores tanto al individuo como al grupo. Esto se evidencia en el simple hecho de que si alguien es objeto de alguna agresión busca abrigarse en su grupo de referencia para reconstruirse. De este modo, prosiguen los autores, los grupos informales contrabalancean los efectos destructores de la violencia verbal (Chanlat \& Bédard, 1997) casi siempre malintencionada del chisme.

El espacio físico donde la palabra se libera, y con ella todo tipo de sentimiento, puede ser cualquiera desde un baño, el bar, el parqueadero, la sala de juntas, no importa. Si los dirigentes estuvieran más atentos, podrían potencializar no solo los espacios físicos, sino lo que en ellos se "conversa" de manera favorable para la organización y no verían este tipo de comportamientos algo perjudicial o incluso algo construido deliberadamente por "esos otros" en su contra. La capacidad de construcción o de destrucción que tiene la palabra supera el mero mensaje de un emisor a un receptor, dado que son personas las que intervienen en el diálogo, luego del cual ellas pueden influenciarse mutuamente confirmando o negando sus respectivas identidades por un comentario, un gesto, una observación (Chanlat, 1996). Es por tanto, es mediante la calidad de los encuentros con los demás que, mutuamente, nos construimos o nos destruimos. (Jean Paul Sartre citado en Chanlat, 1996).

Cobra aquí importancia, entonces, la ética de la palabra de los dirigentes como cualidad indispensable. La incoherencia entre lo que pregonan con su palabra y lo que hacen con sus acciones los lleva a perder legitimidad ante sus subalternos y a ser cuestionados por tener una doble palabra (Bédard, 1996). El reproche vendrá con distintas ropas, agazapado en el chismorreo, en la desobediencia consiente, en la baja productividad deliberada y esos efectos no podrán ser superados ni por la más fabulosa receta administrativa de la lógica eficientista occidental. 
El deterioro de la dignidad del trabajador se ocasiona frecuentemente a través del lenguaje violento. Existen varios ejemplos en empresas colombianas que han sido estudiadas con el propósito de hallar manifestaciones de trato inhumano, la mayoría realizadas por el grupo Humanismo y Gestión de la Universidad del Valle. La narración siguiente es un ejemplo de violencia verbal en el que es evidente un sentimiento de agresión muy fuerte: (Cruz-Kronfly \& Rojas, 2008)

"Desde 1984, época en que entré a la empresa, trabajé obligatoriamente de 7:00 Am a 7:00 PM, incluyendo sábados y domingos. Además, me soporte un supervisor cuyo trato verbal y actitud eran indeseables. Cuando uno no está enseñado a que lo traten mal, se le hace duro. Una vez, en una reunión él empezó a mentar madres e hizo alarde de su maltrato. Yo me puse a llorar, y me dijo:

- ¿Vos por qué lloras?

- Y yo le dije: porque no estoy acostumbrada a que me traten así.

- Pues váyase acostumbrando, me respondió, porque aquí el que no sepa un culo se va"

En su investigación Kronfly y Rojas (2008), a manera de conclusión, señalan: un directivo de cierto rango o un supervisor no cometen en general un acto de desconocimiento de la humanidad del subordinado solo por satisfacer su placer de maldad, La mayoría de las personas que cometen actos inhumanos, lo hacen en virtud de una lógica que en sí misma precipita los actos, que obligan y determina el actuar. Por supuesto, esto no los hace inocentes.

Pero la comunicación, no solo se evidencia a través del lenguaje, la lengua o el habla. También existe el lenguaje corporal compuesto por los gestos que manifiestan estados de ánimo y dan cuenta de posturas claras de un individuo frente a otro. Es lo que se denomina el lenguaje no verbal que, por supuesto, también es un medio para relacionarse positiva o negativamente con los demás.

La palabra y el lenguaje no verbal

Para Cruz Kronfly (2007) el mundo de lo humano es una textura simbólica de gestos y palabras. Las relaciones que surgen como consecuencia del trabajo y los procesos productivos no escapan a esta consideración como tampoco escapa el conflicto, donde el uso de un lenguaje claro, que evite la ambigüedad de los planteamientos, es un elemento muy importante de la integración ${ }^{4}$ a manera de

4 Para Follet existe tres caminos para la resolución del conflicto en la organización: uno es mediante la dominación es decir, la victoria de una de las partes sobre la otra; otro el acuerdo, en el que las partes ceden en algunos de sus planteamientos; y, por último, al integración en el que la solución confluye en un punto de convergencia entre ambas partes, sin sacrificar nada a cambio. 
convergencia de interés para su resolución. (Follet citado en Dominguez \& Garcia, 2005).

Gran parte de conflictos dentro de la organización surgen, precisamente, por el modo como se enuncian las órdenes: los gestos, las posturas corporales, los énfasis, la connotación, hasta la mirada que acompaña su emisión, todo lleva un significado (Cruz-Kronfly, 2007), de superioridad o de inferioridad, de poder o de sumisión. Según Kronfly, el lugar que alguien ocupa en la jerarquía organizacional determina las palabras, los acentos y el carácter de las miradas, así como las licencias y los límites del uso simbólico.

Entre nosotros los humanos, sonreír, reír, fruncir el ceño, alzar las cejas son un conjunto de señales que muestran un estado interno momentáneo, en un momento determinado, que otra persona reconoce y entiende. Esto es lo que Llinás denomina "prosodia" biológica, una forma generalizada de comportamiento abstracto, una gesticulación externa de un estado interno (Llinás, 2002). Esa "prosodia" es, quizá, lo que más contribuye a determinar la calidad de las relaciones entre los seres humanos y, en definitiva, lo que determina la percepción del buen o mal "trato" entre ellos y del directivo hacia ellos, dentro y fuera de la organización.

\section{CONCLUSIONES}

Las diversas situaciones presentadas aquí, pueden ser halladas con mayor o menor similitud en organizaciones que tal vez el lector conozca o quizá en las que haya hecho parte. Seremos parte de quienes usan el lenguaje como expresión de nuestras propias debilidades? O quizá como un vínculo para ponernos en el lugar del "otro" y comprender su realidad?. Sea cual sea nuestra particular situación, es indudable la marca que deja la palabra en nuestro comportamiento y en la acción de nuestro interlocutor.

Aunque el dominio del lenguaje no es exclusivo del ser humano, la vocalización de la intención que, es la palabra, tal vez si lo sea. Así como la imaginación precedió al lenguaje, la intención precede a la acción. Una acción es irreversible, es el daño generado con la palabra. En un fuerte llamado de atención citaré de forma textual un texto de Pierre Lagendre, hallado en Chanlat y Bédard: "Por haber desconocido las realidades del discurso, la Administración ha recibido aquí y allá fuertes contradicciones. Pensad en esta lección y podréis prepararte para comprender que la especie hablante no se maneja como si fuera ganado". (Chanlat \& Bédard, 1 


\section{REFERENCIAS BIBLIOGRAFICAS}

Aktouf, O. (1995). Antropologia de la comunicación y la cultura empresarial. Caso Cascades. Cuadernos de Administración. Univalle, 20.

Aktouf, O. (1998). Administración: entre tradición y renovación. Cali. Valle: Gaetan Moran.

Aktouf, O. (2002). El simbolismo y la cultura organizacional. De los abusos conceptuales a las lecciones de campo. Ad-Minister Universidad Javeriana, 1.

Bédard, R. (1996). En el corazón del oficio del dirigente: el ser y los valores. Cuadernos de Administración. Univalle, 23.

Cruz-Kronfly. (2007). Las palabras y los gestos en el tejido organizacional. In C. N. P. A. Univalle (Ed.), Del humanismo admisnitativo en crisis. Una ruptura paradigmática. Cali. Colombia.

Cruz-Kronfly, \& Rojas, W. (2008). La noción de inhumanidad y culturas híbridas en algunas organizaciones colombianas. In F. C. Kronfly (Ed.), Racionalidad Instrumental y Gestion. Cali, Colombia: Universidad del Valle.

Cruz-kronfly, F. (2007). Las palabras y los gestos en el tejido organizacional. In F. C. K. Compilador (Ed.), Del humanismo administrativo en crisis: Rupturas paradigmáticas. Colección: Nuevo pensamiento administrativo. Cali. Colombia: Univalle.

Chanlat, A. (1996). El oficio del dirigente: Gran empresario o buen dirigente? Cuadernos de Administración. Univalle, 15(23).

Chanlat, A., \& Bédard, R. (1997). La Administración, una cuestion de palabra. Tecnología Administrativa. Universidad de Antioquia.

Chomsky, N. (1975). Reflexiones sobre el lenguaje. Barcelona España: 1985.

Dominguez, R., \& Garcia, S. (2005). Conflicto constructivo e integración en la obra de Mary Parker Follet. Revista Athenea Digital. Universidad Autónoma de Basrcelona 007.

Etkin, J. (1993). La doble moral de las organizaciones. Los sistemas perversos y la corrupción institucionalizada. Buenos Aires, Argentina: Mc Graw Hill.

Gramsci, A. (1916). Socialismo y Cultura, from http://www.archivochile.com/Ideas Autores/gramscia/d/gramscide0020.pdf

Gramsci, A. (1967). La formación de los intelectuales. Mexico Editorial Grijalbo.

Hatch, M. J. (1997). Organization Theory. Modern Symbolic and postmodern perspectives. New York.: Oxfor University. 
Llinás, R. (2002). El cerebro y el mito de yo. El papel de las neuronas en el pensamiento y el comportamiento humanos: Norma Editores.

RAE. (Ed.) (2001) (22ava Edicion ed.). España: Real Academia Española.

Saavedra, J. (2009). Descubriendo el lado oscuro de la gestión: Los critical studies o una nueva forma de abordar los fenómenso organizacionales Investigación y reflexion. Universidad Militar Nueva Granada, 27(2).

Saussure, F. D. (1945). Curso de lingüistica General Losada.S.A. (Ed.)

Serres, M. (1996). La Comunicación: Hermes I Barcelona: Anthropos

Wittgenstein, L. (1999). Investigaciones filosóficas. España: Ediciones Altaya. S.A. 